\title{
ANÁLISE CRÍTICA SOBRE O DESEQUILÍBRIO FINANCEIRO DOS MUNICÍPIOS NO MODELO DE FEDERALISMO FISCAL BRASILEIRO
}

\author{
Cintya Maria Nishimura Durães* \\ Maria de Fátima Ribeiro**
}

RESUMO: O presente artigo aborda o desequilíbrio financeiro dos municípios no modelo de federalismo fiscal brasileiro. Objetiva-se demonstrar que o modelo atual não contribui o quanto poderia para a redução das desigualdades econômicas regionais. Será pesquisado qual o papel do federalismo cooperativo dentro da sistemática delineada pelo texto constitucional. A partir das normas que regulamentam o tema, procurar-se-á compreender como tem funcionado na atualidade a questão. A complexidade normativa tributária e o excesso de burocracia não contribuem para que o federalismo cooperativo atenda adequadamente às necessidades dos municípios, aos quais foram atribuídos muitos serviços públicos de atendimento à população, que precisam de recursos financeiros suficientes para ser bem realizados. Como método para o desenvolvimento da pesquisa será aplicado o hipotético-dedutivo, apontando como hipótese a premissa de que nos moldes como vem sendo praticado, o federalismo brasileiro não conduz ao pleno cumprimento dos princípios e objetivos constitucionais. Ao final, concluiu-se que o país precisa rever sua forma de repassar as receitas tributárias, especialmente em relação aos municípios que arcam com encargos desproporcionais ao produto da arrecadação que realizam e aos valores recebidos pelos repasses dos Estados e da União.

PALAVRAS-CHAVE: Federalismo fiscal brasileiro; Federalismo cooperativo; Desequilíbrio municipal; Repasses de receitas; Reforma tributária.

\section{A CRITICAL ANALYSIS ON FINANCIAL DISORDER IN MUNICIPALITIES WITHIN THE BRAZILIAN FEDERAL FISCAL MODEL}

ABSTRACT: The financial disorder of municipalities within the Brazilian fiscal

\footnotetext{
" Mestranda do Programa de Mestrado da Universidade de Marília (UNIMAR). Bolsista Capes PROSUP. Advogada. E-mail: cnddireito@gmail.com

** Doutora em Direito pela Pontifícia Universidade Católica de São Paulo (PUC/SP). Docente Titular do Programa de Mestrado e Doutorado da Universidade de Marília (UNIMAR), Brasil.
} 
federal model is analyzed. Current fiscal model does not contribute sufficiently for the reduction of regional economic inequalities. The role of cooperative federalism within the tenets of the Constitution and the manner it has functioned within the laws are investigated. The complex tax system and excess of bureaucracy are not helpful for cooperative federalism to attend properly the needs of the municipalities with many public services for the population. Municipalities require huge sums of money so that services would be undertaken satisfactorily. The hypothesis-deduction method will be employed, or rather, Brazilian federalism currently applied does not satisfactorily lead towards the compliance of constitutional principles and aims. Results show that Brazil should revise its mode of transferring budget, particularly to municipalities that have to bear huge loads in proportion to the budget received when transferred from the state and federal governments.

KEY WORDs: Brazilian fiscal model; Cooperative federalism; Municipal disorder; Budget transference; Tax reform.

\section{INTRODUÇÃO}

O Sistema Tributário Nacional é formado pelo conjunto de normas e princípios que regulam as atividades relacionadas à arrecadação de tributos pelos entes federativos que compõem o Estado brasileiro. Esse sistema é disciplinado pela Constituição Federal de 1988, nos artigos 145 a 162, pelo Código Tributário Nacional, leis complementares, resoluções do Senado Federal, leis federais, estaduais e municipais e demais desdobramentos legislativos.

Os valores recolhidos a título de tributação formam as receitas tributárias, que são atribuídas aos entes que compõem a federação, segundo as regras constitucionais. A Carta Magna dispõe sobre a competência da União, dos Estados, do Distrito Federal e dos municípios para a instituição e cobrança dos tributos, regula a repartição do montante arrecadado, determinando qual parcela dos impostos serão repassados às municipalidades pelos outros membros.

O Brasil, em 1889 com a proclamação da República, adotou o Federalismo como forma de Estado, centralizando o poder na União Federal. Embora a liberdade dos Estados independentes tenha sido abdicada, a autonomia se mantém, acrescentando-se outras competências atribuídas ao longo do texto constitucional. 
Desde o início, o modelo de federalismo praticado no país vem sofrendo duras críticas por parte dos estudiosos do assunto, pela alta concentração tributária da União, em detrimento dos demais membros, que ficaram com a maior parte dos encargos, desequilibrando-se a relação entre a quantidade de recursos financeiros que pertencem àqueles e o volume de prestação de serviços públicos aos cidadãos, principalmente no caso dos municípios.

Compreende-se que o formato federalista fiscal e o cooperativo, na forma como estão sendo exercidos atualmente não atendem aos objetivos fundamentais insculpidos no artigo $3^{\circ}$ da Constituição Federal de 1988. A União detém para si expressiva quantidade de receita tributária, mas são os municípios que diretamente realizam o atendimento das necessidades da população por estarem mais próximos, fisicamente, dos contribuintes.

Destaca-se que o sistema tributário nacional é regido pelos princípios constitucionais que estabelecem as diretrizes para a garantia da construção de uma sociedade livre, justa e solidária, o desenvolvimento nacional, a erradicação da pobreza e a marginalização, dentre outras. Todas as normas que formam o ordenamento jurídico pátrio são condicionadas a atender aqueles postulados, sob pena de não serem consideradas válidas.

Todavia, a alta complexidade do conjunto normativo tributário e o excesso de burocracia fazem com que o formato federalista sofra alterações que repercutem diretamente sobre a sociedade brasileira. O sistema tributário nacional precisa ser reformado, permitindo que o federalismo fiscal brasileiro e o federalismo cooperativo alcancem o equilíbrio ideal.

Diante do desequilíbrio financeiro que os municípios vêm sofrendo, em razão da forma pela qual são distribuídos os montantes dos tributos arrecadados, objetiva-se demonstrar que o modelo atual de federalismo fiscal praticado no país não contribui o quanto poderia para a redução das desigualdades econômicas regionais.

Justifica-se a presente pesquisa pela importância da temática relativa ao federalismo cooperativo, consolidado com a Constituição Federal de 1988 e que atualmente vem gerando discussões na doutrina e na jurisprudência. Ademais, debate-se a reestruturação do sistema tributário nacional, que se encontra distante 
da realidade modificada pela evolução social e tecnológica ocorrida ao longo do tempo.

A metodologia empregada se consubstanciará na pesquisa bibliográfica, a partir da qual se farão análises dos conteúdos pelo método hipotético-dedutivo.

\subsection{O FEDERALISMO NAS CONSTITUIÇÕES BRASILEIRAS}

Federalismo é a união indissolúvel de Estados, que abdicam de sua independência, mas conservam sua autonomia, para formar um só Estado Federal regido por uma Carta Constitucional. Após a união de províncias ou colônias independentes, em busca de fortalecimento econômico e político, formando a federação, não há possibilidade de separação dos membros.

Na Federação, os Estados que dela participam (Estados-membros) estão subordinados a uma Carta Magna, que lhes confere competências, tanto quanto ao Estado Central (União). Nela, a União e os Estados-membros são autônomos, mas não soberanos, já que encontram limites em seu agir na Constituição, que, encimando-os, dá validade aos atos jurídicos que praticam (CARRAZZA, 2013, p. 156 , grifos do autor).

No Brasil, a adoção do modelo federalista ocorreu por meio do decreto n. 1, de 15 de novembro de 1889, data em que foi proclamada a República no país (MARTINS, 2017). Antes de ser implantado, o cenário político vigente consistia em uma monarquia constitucional, ou seja, o poder do monarca era limitado pelas normas constitucionais (MARTINS, 2017).

A promulgação da Carta Magna de 1891 dispõe na redação de seu artigo $1^{\circ}$ expressamente:

A Nação brasileira adota como forma de Governo, sob o regime representativo, a República Federativa, proclamada a 15 de novembro de 1889, e constitui-se, por união perpétua e indissolúvel das suas antigas Províncias, em Estados Unidos do Brasil. (grifo nosso). 
A previsão no texto constitucional tornou inequívoca a opção pelo formato de Estado brasileiro, enfatizando a importância das normas constitucionais para a sua existência.

A adoção da espécie federal de Estado gravita em torno do princípio da autonomia e da participação política e pressupõe a consagração de certas regras constitucionais, tendentes não somente à sua configuração, mas também à sua manutenção e indissolubilidade [...] (MORAES, 2012, p. 286).

O formato de Estado Federal envolve aspectos políticos, mas também fiscais, ou seja, o federalismo possui ramificação ligada às atividades arrecadatórias dos tributos, suas normas e princípios, competências e repartição das receitas, em que um ente possui participação no montante auferido por outro (MANSUR, 2017).

A primeira Constituição brasileira da era republicana foi a de 1891. Após esta, vieram as de 1934, 1937, 1946, 1967, Emenda n. 1/1969 e 1988. Todas as Cartas Magnas que vigeram no país, inclusive a atual, foram inspiradas em Constituições de outros países, seguindo as tendências mundiais.

A promulgação da Carta Magna de 1934 deu início à implantação do modelo de federalismo cooperativo no país, concentrando a maior parte da arrecadação na União (PARCELLI, 2015). Os municípios passaram a ter competência para instituírem seus próprios tributos:

Art. 13. Os Municípios serão organizados de forma que lhes fique assegurada a autonomia em tudo quanto respeite ao seu peculiar interesse; e especialmente:

$[\ldots]$

II - a decretação dos seus impostos e taxas, a arrecadação e aplicação das suas rendas;

$[\ldots]$.

Todavia, em 1937 iniciou-se um processo de alteração significativa no sistema federalista, pois aquela Norma Maior passou a permitir mutações geográficas e políticas entre os Estados, como os movimentos de incorporação, subdivisão, 
desmembramento ou mesmo formação de novos Estados (BRASIL, 1937).

É possível afirmar que a partir da Carta de 1937 a União passou a concentrar cada vez mais o produto da arrecadação e o poder para instituir novas fontes de receitas oriundas de impostos. Concomitantemente, os Estados acabaram perdendo parte de suas competências (PARCELLI, 2015). Analisando o cenário daquele período, percebem-se mudanças significativas no federalismo brasileiro.

A Constituição Federal de 1946 proporcionou aos entes federativos do Estado brasileiro a retomada de parte de sua autonomia, permitiu a criação de novas fontes de receitas tributárias à União, além de instituir a competência comum entre União, Estados, Distrito Federal e municípios para cobrar contribuição de melhoria em decorrência de valorização de imóvel por obra pública (PARCELLI, 2015).

Com as trocas de Cartas Magnas no Brasil, o formato federalista foi se modificando, passando a ser moldado pelos regimes políticos que estavam no poder. A construção do sistema tributário nacional, na década de 1960, impactou-o diretamente, por trazer um conjunto de normas e princípios que limitavam o exercício das competências tributárias (PARCELLI, 2015).

Em 1965, com a Emenda n. 18 foram criados os fundos de participação dos Estados e o dos municípios. Antes disso, a União realizava distribuição vertical de receitas. Na forma horizontal cada ente é responsável por seus próprios tributos; na vertical, as verbas podem ser indiretas por meio da cobrança de parcela do tributo realizada por ente distinto da respectiva competência (MANSUR, 2017).

A Constituição Federal de 1967 inovou ao prever um capítulo próprio para o sistema tributário. Na legislação anterior, o assunto inseria-se no capítulo I, dedicado às disposições preliminares sobre a organização federal (BRASIL, 1946). O advento do Código Tributário Nacional, em 1966, provavelmente favoreceu essa reorganização no texto constitucional.

No ano de 1969 a Emenda n. 1 editou o texto da Constituição de 1967. Essa alteração se deu em razão da instalação do governo militar no Brasil. Embora o poder político tenha se concentrado no Executivo Federal, mantiveram-se os repasses da União para os Estados, o Distrito Federal e os municípios.

Na elaboração da Constituição Federal de 1988, além da redemocratização do país houve a elevação dos municípios ao status de entes integrantes do pacto 
federativo, dotados de autonomia, consoante a redação do artigo 18, caput, da Lei Maior: "A organização político-administrativa da República Federativa do Brasil compreende a União, os Estados, o Distrito Federal e os Municípios, todos autônomos, nos termos desta Constituição"(grifo nosso).

Como ensina Hely Lopes Meirelles (2008, p. 47),

A Federação Brasileira não dispensa e nem prescinde do Município na sua organização constitucional. Segue-se, daí, que o Município Brasileiro é entidade político-administrativa de terceiro grau, na ordem descendente da nossa Federação: União - Estados - Municípios [...]. O município brasileiro sempre fez parte da federação. E a Constituição de 1988 assim o declarou em seus arts. $1^{\circ}$ e 18 , corrigindo essa falha.

No Estado Federal uma série de competências é distribuída entre todos os seus participantes, possibilitando o exercício de suas respectivas funções. A cada membro da federação é permitida a instituição de sua fonte normativa e de tributos a serem arrecadados, devendo haver observância dos limites traçados pela Lei Maior.

Todavia, a União concentra a maior parte do montante arrecadado pelo país, enquanto que aos demais entes federativos foram atribuídos as prestações da maioria dos serviços públicos, principalmente no caso dos municípios, que estão em contato mais próximo com os cidadãos, dependendo dos repasses de verbas para atenderem tais necessidades, já que sua arrecadação não é proporcional aos seus encargos.

A Constituição de 1988 buscou descentralizar a atividade arrecadatória, mas a União detém poder sobre os demais entes federados com a manutenção da dependência financeira desses. Isso não condiz com o propósito de autonomia previsto pela Carta Magna.

Visando garantir a independência, pelo menos em parte, do município no atual sistema tributário brasileiro, sua arrecadação recebeu um reforço constitucional com a finalidade de diminuir as desigualdades regionais e, em contrapartida, contribuir para a conquista dos objetivos fundamentais da República, dispostos no artigo $3^{\circ}$, da Constituição Federal, considerando que é: 
[...] possível ocorrer desequilíbrio na arrecadação, em virtude de fatores socioeconômicos alterarem os ingressos e receitas, a Constituição estabelece forma de repartição das receitas tributárias (arts. 157 - 162) [...] de modo que entes menores tenham recursos suficientes para atender a suas necessidades (OLIVEIRA, 2015, p. 113-115).

É o produto arrecadado pelos entes superiores e sua respectiva partilha para os inferiores (arts. 157 a 161) e também por meio das transferências intergovernamentais os expedientes encontrados pelo legislador para promover o equilíbrio financeiro do município, pode-se afirmar que por meio da autonomia financeira são asseguradas a autonomia administrativa e a autonomia política daquela unidade da Federação (COSTA, 2015).

Para compreender como funcionam as transferências intergovernamentais, examinar a norma presente no texto constitucional e compará-la com o que vem sendo realizado na prática é imprescindível. O modelo de federalismo adotado pelo Estado brasileiro está previsto no art. $60, \S 4^{\circ}$, inciso I, da Constituição Federal, sendo considerado cláusula pétrea, ou seja, é vedada a deliberação sobre proposta de emenda tendente a aboli-lo.

No tópico seguinte será abordada a repartição das receitas de acordo com a previsão da Carta Magna vigente e as implicações da dependência financeira que Estados, Distrito Federal e municípios têm dos repasses financeiros da União.

\section{A REPARTIÇÃO DAS RECEITAS NA CONSTITUUIÇÃO FEDERAL DE 1988 E AS CONSEQUÊNCIAS DA DEPENDÊNCIA FINANCEIRA DOS ENTES FEDERAIS EM RELAÇÃO À UNIÃO}

A repartição de receitas tributárias ou Federalismo Fiscal, a partir do advento da nova ordem constitucional em 1988, tornou-se menos equilibrada, concentrando mais impostos sob a arrecadação da União, além de permitir a instituição de outras fontes, como as contribuições, que não ingressam no montante dividido com os demais entes federativos.

A Constituição Federal de 1988 dispõe nos artigos 157 e seguintes acerca 
dessa repartição das receitas tributárias pertencentes à União a título de impostos, ou seja, os repasses que são feitos aos Estados, ao Distrito Federal e aos municípios, por meio dos fundos de participação dos respectivos entes federativos.

A classificação da repartição das receitas distingue-as em diretas e indiretas. As receitas diretas são aquelas em que o próprio ente político realiza a arrecadação e apropria-se da parcela que lhe é cabível sem a necessidade de intermediação de outro ente. Os tributos que se enquadram nessa modalidade estão previstos, por exemplo, no art. 158 da Constituição Federal, que dispõe sobre as receitas tributárias pertencentes aos municípios.

Já as receitas indiretas são aquelas repartidas e redistribuídas aos fundos de participação, como ocorre nas transferências intergovernamentais constitucionalmente regulamentadas no art. 159. Moraes (2012, p. 911) afirma que "O texto constitucional reserva à lei complementar a regulamentação dos preceitos básicos para garantir a efetiva realização do repasse de verbas decorrente da repartição constitucional das receitas tributárias".

O modo de repartir e de classificar as receitas tributárias ocorre em relação aos impostos, visto que esses não são vinculados a finalidades específicas, como ocorre com a espécie de tributo denominada Contribuição de Intervenção no Domínio Econômico - CIDE, cuja vinculação impede a aplicação dos valores arrecadados em fim diverso do apontado pela norma.

O artigo 157 da Lei Maior regula a transferência da União para os Estados e o Distrito Federal, de receitas originárias da arrecadação de imposto de renda e proventos de qualquer natureza, que incidirem na fonte sobre rendimentos pagos, a qualquer título, pelos respectivos entes, suas autarquias e fundações, assim como, $20 \%$ sobre o produto da arrecadação da União sobre impostos instituídos por meio de lei complementar, que não estejam no rol do artigo 153, não sejam cumulativos e não possuam fato gerador ou a base de cálculo próprio dos que já estão previstos no texto constitucional.

Quanto aos municípios, o artigo 158 descreve que a esses devem ser destinadas receitas originárias da arrecadação do imposto de renda e proventos de qualquer natureza, incidente na fonte, sobre os rendimentos pagos, a qualquer título, pelos respectivos entes, suas autarquias e fundações, assim como $50 \%$ do imposto 
estadual sobre a propriedade de veículos automotores licenciados nos respectivos territórios e $25 \%$ do imposto estadual sobre operações relativas à circulação de mercadorias, prestações de serviços de transporte interestadual, intermunicipal e de comunicação.

O parágrafo único do artigo 158 pormenoriza que as parcelas mencionadas no caput, serão creditadas no mínimo em 3/4 para o caso das operações relativas à circulação de mercadorias e prestações de serviços realizadas em seus territórios, e, até no mínimo $1 / 4$, de acordo com a respectiva lei estadual.

Na sequência, a redação do artigo 159 afirma que a União entregará 49\% do produto arrecadado com o imposto sobre renda e proventos de qualquer natureza, bem como do imposto sobre produtos industrializados (IPI), nas seguintes proporções: 21,5\% ao Fundo de Participação dos Estados e do Distrito Federal; 22,5\% ao Fundo de Participação dos municípios; 3\% para programas de financiamento do setor produtivo das regiões Norte, Nordeste e Centro-Oeste; $1 \%$ ao fundo de participação dos municípios em dezembro de cada ano e mais 1\% em julho de cada ano; $10 \%$ do imposto sobre produtos industrializados aos Estados e Distrito Federal, proporcionalmente ao valor das respectivas exportações desses produtos; $29 \%$ do imposto sobre a contribuição de intervenção no domínio econômico (CIDE) para Estados e Distrito Federal (grifo nosso).

A partir das regras acima dispostas, pode-se chegar a algumas conclusões: o federalismo fiscal brasileiro está disciplinado em lei, mas suas normas são complexas. A União possui um rol de impostos no artigo 153 da Constituição Federal, no qual estão previstos sete tipos, podendo instituir outros por meio de lei complementar, conforme autoriza o inciso I do artigo 154, além da possibilidade de criar impostos extraordinários, segundo o inciso II.

Justifica-se que o montante arrecadado pelo poder central seja maior em relação aos demais entes federativos pela soma de seus gastos, haja vista que a manutenção das atividades na esfera federal possui custo elevado como, por exemplo, a defesa das fronteiras. Todavia, a União pode criar outras fontes de arrecadação, como é o caso das contribuições e dos impostos extraordinários, que não entram na repartição com os Estados, Distrito Federal e municípios.

O legislador constitucional impõe à União a entrega de $49 \%$ do produto 
da arrecadação do imposto de renda e proventos de qualquer natureza e imposto sobre produtos industrializados aos outros membros da federação, em proporções bem delimitadas, como foi visto, ao passo que os encargos suportados por aqueles crescem a cada dia. Quase metade do total auferido deve ser destinada aos demais membros.

Estados e Distrito Federal são autorizados pelo texto da Lei Maior, artigo 155, a instituir apenas três impostos: transmissão causa mortis e doação de quaisquer bens ou direitos (ITCMD); relativo à circulação de mercadorias e prestação de serviços de transporte interestadual e intermunicipal e de comunicação (ICMS); sobre a propriedade de veículos automotores (IPVA). O dispositivo contém um rol extenso de parágrafos e incisos que regulamentam desde a fixação das alíquotas e bases de cálculo até a não incidência em determinadas circunstâncias, dos respectivos tributos.

Os municípios, do mesmo modo, podem instituir três impostos: sobre a propriedade territorial urbana (IPTU); sobre a transmissão inter vivos de imóveis ou direitos reais sobre esses (ITBI); sobre serviços de qualquer natureza (ISSQN). Assim como no caso dos Estados e Distrito Federal, os municípios também possuem no texto constitucional parágrafos e incisos que apontam a incidência, a não incidência e as alíquotas.

A Constituição Federal de 1988 conferiu competência tributária a todos os entes (União, Estados, Distrito Federal e Municípios). Permitindo a cada um deles a criação, majoração, lançamento, fiscalização e cobrança de seus tributos (TRENNEPOHL, 2011, p. 94).

Ocorre que a União concentra mais da metade dos montantes arrecadados com a tributação, mas os encargos que são atribuídos aos municípios são os que a população fazem uso diariamente, como educação, saúde, transporte público, segurança pública, dentre outros. Os repasses feitos não atendem adequadamente essas necessidades, sendo comum a falta de verbas para muitos serviços.

A Constituição Federal de 1988, ao redistribuir competências e encargos entre os três níveis da federação, está na gênese do processo de deterioração do federalismo fiscal, com efeitos danosos 
na tributação e, em consequência, na competitividade das empresas brasileiras (FERREIRA, 2016, p. 30).

A crítica da doutrina recai sobre a estrutura de redistribuição com razão, pois, quando a União Federal concede isenções ou incentivos fiscais, por exemplo, deixa de arrecadar com isso e os reflexos se estendem para os demais entes. Em momentos de crise financeira, medidas nesse sentido são implantadas para evitar que a economia desaqueça, gere desempregos em massa e outras consequências sociais, mas os encargos não são reduzidos.

Todavia, os benefícios fiscais concedidos limitam-se a incidir sobre os impostos da União, restando excluídos disso as contribuições especiais que não são sujeitas à repartição.

Independentemente das percepções sobre o pacto fiscal federativo implantado pela Constituição da República Federativa do Brasil de 1988, o fato é que as competências tributárias ou o poder de tributar estabelecido na Carta Magna, bem como a repartição de receitas tributárias da União destinada aos Estados-membros, Distrito Federal e Municípios, têm o condão de assegurar que tais entes possam cumprir as atribuições e deveres constitucionalmente fixados pelo Constituinte a cada um dos entes federados, especialmente na execução de políticas públicas (PARCELLI, 2015, p. 80).

A Constituição Federal pretende que a repartição das receitas tributárias assegure o cumprimento dos compromissos atribuídos a cada ente federativo, mas a diminuição de verba reduz a quantidade e a qualidade dos serviços públicos prestados aos cidadãos. Percebe-se que a divisão das competências e das receitas não é proporcional aos encargos distribuídos; qualquer alteração que ocorra nos montantes auferidos pela União repercute sobre Estados, Distrito Federal e municípios.

Desse modo, acentuam-se as desigualdades econômicas regionais, a guerra-fiscal entre Estados, o endividamento dos governos cresce e o federalismo cooperativo, isto é, a partilha de receitas entre as três esferas de governo, desestabilizase. Os municípios são os mais atingidos, especialmente os de pequeno porte, com receita tributária ínfima, que praticamente dependem dos repasses de verbas para se manter. 
O Sistema não produz solidariedade nacional, ao contrário, os três entes são concorrentes, não assumem riscos e nem projetam efeitos em modelos mais racionais e que assimilem um cooperativismo centralizado - apenas na arrecadação - capaz de gerar mais receitas e menos efeitos negativos (FERREIRA, 2016, p. 36).

O Federalismo Cooperativo deve atender aos propósitos pelos quais foi adotado na Constituição Federal de 1988, atuando na diminuição das externalidades que afetam o desenvolvimento do país. As decisões tomadas pelo poder central em matéria de arrecadação tributária precisam ser cuidadosamente avaliadas, quanto aos efeitos que produzirão para os Estados, o Distrito Federal e os municípios.

O caráter cooperativo de nosso federalismo parece inegável ao se constatar que quase metade da arrecadação de dois dos impostos da União destinam-se aos demais entes da Federação e, sob tal aspecto, o princípio da solidariedade entre os entes da federação parece estar atendido. A distribuição de tais verbas, todavia, e os objetivos que tendem a atingir são aspectos que merecem análise mais detida, a fim de se aferir o real atendimento de referido princípio (MANSUR, 2017, p.43).

De fato, o formato federalista implica em uma atuação cautelosa por interligar esferas governamentais, buscando a promoção do bem comum para a coletividade. Contudo, se a dependência financeira for um limitador do desenvolvimento de algum (ns) membro (s), significa que há problemas em relação à autonomia. Um município que seja extremamente dependente de verbas repassadas pelos Estados e pela União para subsistir não pode ser considerado autônomo, pelo menos, não financeiramente.

A União mantém com a dependência financeira dos outros membros da federação uma concentração de poder sobre esses, ou seja, "[...] força a submissão do poder local ao poder central [...]" (DOMINGUES, 2007). Retrocede-se à condição anterior a 1988, isto é, à ideia de centralização, e não a descentralização das funções vitais ao país.

Nos dias atuais em que a evolução da sociedade e da tecnologia exige a modernização dos sistemas, o Brasil tem o dever de acompanhar as mudanças, 
sob pena de ser taxado de Estado não desenvolvido, produzindo consequências desastrosas para a economia interna e as relações com o mercado externo.

O modelo de federalismo fiscal cooperativo adotado no Brasil, entretanto, não pode reduzir-se ao apoio conjuntural da União. É preciso aprimorar mecanismos que garantam a autonomia financeira dos entes subnacionais, mesmo em face de políticas fiscais anticíclicas, a fim de evitar a dependência de auxílios emergenciais, sob liberalidade do Poder Executivo Federal [...] (ASSUNÇÃO, 2010, p. 33-34).

Se a Constituição de 1988 elevou o status das municipalidades é porque o legislador entendeu que haveria condições para isso. Mas, para que haja equilíbrio entre as receitas tributárias e os encargos dos entes federativos, reestruturar o sistema tributário nacional é uma das condições. As atuais complexidades somadas à burocracia operam contrariamente ao desenvolvimento do país.

\section{FEDERALISMO FISCAL BRASILEIRO E SISTEMA TRIBUTÁRIO NACIONAL: A NECESSIDADE DE UMA REFORMA TRIBUTÁRIA}

O federalismo fiscal brasileiro condiciona constitucionalmente o sistema tributário nacional, com princípios e normas expressas na Lei Maior, nos artigos 145 a 162, detalhando a repartição das receitas arrecadadas, assim como as limitações ao poder de tributar. Reciprocamente, o sistema tributário produz reflexos sobre o federalismo fiscal, ao prever a discriminação dos impostos com seus respectivos fatos geradores e base de cálculo no Código Tributário Nacional.

Todavia, o sistema tributário tornou-se muito complexo, sendo formado por uma "colcha de retalhos" com a elaboração de leis infraconstitucionais que se sobrepõem umas às outras sobre um mesmo objeto. Acrescente-se a isso a burocracia excessiva que causa morosidade às atividades relacionadas à res pública.

AConstituição de 1988 operou no sistema tributário umasignificativa reforma, com a reestruturação de diversos impostos. Ademais, como visto anteriormente, consolidou o federalismo cooperativo, direcionando à descentralização tributária, 
visando o desenvolvimento de todas as regiões do país com a menor disparidade possível.

As transformações estruturais subsequentes, que datam da Constituição de 1988, foram dominadas pela temática da Federação e tiveram como principal objetivo reverter o processo de centralização tributária, verificado entre 1968 e 1975 , característico do período autoritário. A descentralização, entretanto, não atualizou os critérios de partilha de receita, hoje superados pelo desenvolvimento econômico e populacional do País, nem enfrentou de forma consistente a temática das relações intergovernamentais no contexto de uma política de equalização fiscal nos moldes das federações do mundo desenvolvido. [...] (DAIN, 1995, p. 36).

Embora a Carta Magna de 1988 tenha renovado a estrutura do federalismo fiscal buscando a descentralização, a legislação tributária não avançou no mesmo sentido, tornando-se um emaranhado de normas que dificulta operações basilares, tanto para os entes públicos, quanto para a iniciativa privada. Existem impostos que possuem base semelhante e são cobrados cumulativamente como, por exemplo, o Imposto sobre Produtos Industrializados (IPI) e o imposto sobre a circulação de mercadorias e prestação de serviços de transporte interestadual, intermunicipal e de comunicação (ICMS), sobre bens industriais (BARRERA, 1999).

Problemas com a cumulatividade ou efeito cascata podem desencadear a denominada guerra fiscal entre Estados. Se um governo estadual renuncia receita fiscal ou concede benefício em troca de investimentos e criação de empregos em seu território, tais fatores ensejarão o endividamento estatal, diante da redução da arrecadação frente a continuidade das despesas (AZEVEDO, 1997).

Sem recursos financeiros suficientes, o Estado buscará junto ao governo federal empréstimos para quitar seus compromissos. Destaque-se que o Brasil é um país de dimensões continentais, formado por 26 Estados, o Distrito Federal e 5.570 municípios. Há regiões que necessitam de mais fomento para se desenvolverem. Diante desse quadro, o federalismo fiscal é um importante meio de diminuição das desigualdades, como determina o artigo $3^{\circ}$ da Constituição de 1988.

Assim, apesar de ter fortalecido o federalismo fiscal cooperativo no país, a Carta Magna de 1988 desencadeou uma série de outros problemas, que podem ser 
solucionados por meio de uma reforma tributária e da diminuição da dependência dos Estados, Distrito Federal e municípios das transferências financeiras da União.

O desequilíbrio financeiro criado pela reforma de 1988 deve ser corrigido por uma nova reforma tributária, que tenha como um dos objetivos conceder maior autonomia fiscal aos estados e aos municípios, e torná-los financeiramente independentes do governo federal. O Brasil, na verdade, nunca funcionou na prática como um regime federalista, pois a União sempre exerceu um grande poder sobre os estados e os municípios das principais capitais. [...] (BARBOSA, 1999, p. 227).

As disputas estaduais ou guerra fiscal tem prejudicado não só os próprios Estados envolvidos, mas também os demais entes federativos. Acredita-se que isso ocorre em razão da pouca descentralização ocorrida na prática. A União exerce ainda muito poder sobre os demais membros, principalmente no que diz respeito à arrecadação tributária. As normas do Código Tributário Nacional em vigor não atendem adequadamente as circunstâncias atuais, sendo muitas delas incompletas, obsoletas, revogadas e não recepcionadas pela nova Lei Maior.

O legislador tentou, então, por meio da criação de inúmeras leis infraconstitucionais soluções paliativas, mas acabou desorganizando o conjunto normativo tributário a tal ponto que atualmente a sociedade tem sentido os efeitos desse desajuste. Reformar o sistema tributário nacional é necessário para que Estados, Distrito Federal e municípios exerçam sua autonomia e sejam mais independentes financeiramente.

O sistema tributário nacional atualmente tem impedido que o país exerça federalismo fiscal mais equilibrado, que por consequência refletiria um melhor desenvolvimento econômico nacional e relacionamento com os mercados externos. Assim, é importante que seja realizada uma reforma tributária que simplifique o conjunto normativo, solucione a questão da guerra fiscal entre os Estados, permita que os entes federativos exerçam a autonomia e obtenham a independência financeira da União.

O Supremo Tribunal Federal (STF), em decisão proferida na Ação Direta de Inconstitucionalidade por Omissão n. 25/DF, no ano de 2016, defende esse 
entendimento: "[...] está claro que o Brasil necessita dessa reforma estrutural, para elevação de sua eficiência econômica, estimulando a produção, o investimento produtivo e a geração de emprego e de renda".

A solução, segundo o Tribunal passa pela uniformização das legislações estaduais relativas ao ICMS para por fim à guerra fiscal, desoneração das exportações e compensação das perdas decorrentes dessa desoneração com o cumprimento do disposto no artigo n. 91 do ADCT.

Enquanto não ocorrerem mudanças estruturais no sistema tributário nacional, o país continuará no ritmo atual, isto é, perdendo oportunidades de desenvolvimento econômico interno e externo, com a lentidão causada pela ausência de vontade política e ação legislativa determinante para resolver os problemas.

Maria de Fátima Ribeiro e Lucas Pires Maciel (2017, p. 99) destacam

Uma questão que merece especial atenção refere-se ao modelo do federalismo fiscal cooperativo e o seu papel atual da forma de governo existente no Brasil. Referido modelo parece também estar em crise. Isto porque há notório desequilíbrio financeiro na distribuição e arrecadação de recursos financeiros, comprometendo a autonomia financeira e política dos estados e municípios. É necessário um ajuste constitucional para uma distribuição mais proporcional às incumbências e encargos de cada ente político.

As discussões tanto na doutrina quanto no Poder Judiciário vêm acontecendo representativamente, mas em razão das diferenças entre os variados interesses presentes dentro do Congresso Nacional, a reforma do sistema tributário prossegue sendo considerada como mera proposta.

O Poder Judiciário é constantemente provocado a se manifestar, para que por meio de seus instrumentos decisórios possa compelir aquele órgão ao cumprimento de suas funções, a sanar as omissões, como exemplifica a ementa a seguir:

Ação Direta de Inconstitucionalidade por Omissão. 2. Federalismo fiscal e partilha de recursos. 3. Desoneração das exportações e a Emenda Constitucional 42/2003. Medidas compensatórias. 4. Omissão inconstitucional. Violação do art. 91 do Ato das Disposições Constitucionais Transitórias (ADCT). Edição de lei complementar. 5. Ação julgada procedente para declarar a mora do Congresso Nacional 
quanto à edição da Lei Complementar prevista no art. 91 do ADCT, fixando o prazo de 12 meses para que seja sanada a omissão. Após esse prazo, caberá ao Tribunal de Contas da União, enquanto não for editada a lei complementar: a) fixar o valor do montante total a ser transferido anualmente aos Estados-membros e ao Distrito Federal, considerando os critérios dispostos no art. 91 do ADCT; b) calcular o valor das quotas a que cada um deles fará jus, considerando os entendimentos entre os Estados-membros e o Distrito Federal realizados no âmbito do Conselho Nacional de Política Fazendária CONFAZ (BRASIL. STF, ADO n. 25/DF, 2016, p. 1).

$\mathrm{Na}$ Ação Direta de Inconstitucionalidade por Omissão (ADO), n. 25, do Distrito Federal (DF), acima transcrita, o Tribunal Pleno do Supremo decidiu por unanimidade pela procedência da demanda, para declarar em mora o Congresso Nacional, quanto à elaboração da Lei Complementar prevista no artigo n. 91 do Ato das Disposições Constitucionais Transitórias.

O Supremo Tribunal Federal também apreciou o Recurso Extraordinário (RE) n. 705.423, interposto pelo município de Itabi/SE, o qual indagou acerca do direito ao recebimento dos valores destinados pela União ao Fundo de Participação dos Municípios (FPM) diante da concessão de isenções e incentivos fiscais pelo ente federal, refletindo-se diretamente sobre os montantes que se repassam aos municípios.

Destaca-se que a temática é pertinente às "discussões sobre pacto federativo, a autonomia financeira dos Municípios e a competência tributária da União", conforme o entendimento de Ribeiro e Maciel (2017). Nota-se que a "autonomia" dos municípios depende da existência de condições proporcionadas pelo ente federal, ou seja, praticamente decorre dos repasses aos fundos de participação dos municípios.

Desse modo, não havendo a transferência monetária da União para os fundos de participação dos municípios, seja por motivo de incentivos fiscais ou isenções concedidas pelo ente federal, os municípios são bastante prejudicados em relação à sua autonomia, além de não terem condições de prestarem os serviços públicos de sua competência.

Diante disso, cabe ao Judiciário decidir com fundamento nos princípios constitucionais, destacadamente, razoabilidade e proporcionalidade, visando 
equilibrar a situação dos municípios e promover segurança jurídica, conforme dispõe a Constituição Federal/88, afirmam Ribeiro e Maciel (2017).

$\mathrm{Na}$ opinião de Fernando Resende (2018), a redução dos desequilíbrios causados pelo modelo de transferências financeiras da União para os demais entes federativos, depende de alterações mais profundas no próprio texto da Constituição, bem como do incentivo à realização de uma cooperação intergovernamental.

Aumentar os repasses feitos pela União e pelos Estados aos municípios poderá contribuir de forma significativa para que esses entes não tenham sua autonomia e a prestação de serviços públicos à sociedade prejudicados. Todavia, a fiscalização da aplicação desses montantes deve ser intensificada, evitando-se a ocorrência de desvios de recursos pelos gestores municipais.

A partir do momento em que o Brasil conseguir modificar as bases que sustentam seu desenvolvimento econômico, alcançará um nível de competitividade maior com os demais países, atrairá investimentos que gerarão benefícios para a sociedade, bem como se adequará à globalização, fator que interfere na economia interna. As mudanças exigem vontade política e ação efetiva para transformar a realidade atual.

\section{CONCLUSÃO}

O federalismo brasileiro, influenciado pelo modelo norte-americano e que teve início com o decreto n. 1 em 1889, foi modificado ao longo do tempo pelas Constituições e momentos políticos pelos quais o país passou. O formato possui desdobramentos, dentre os quais a ramificação fiscal foi objeto de estudo no presente trabalho.

A Carta Magna de 1988 consolidou o federalismo fiscal cooperativo, distribuindo competências para a arrecadação de tributos entre os entes federativos, a repartição das receitas auferidas e o respectivo percentual destinado aos Estados, Distrito Federal e municípios pela União. O papel desse formato é o de atender os princípios e objetivos fundamentais insculpidos na Lei Maior.

Restou notório que a sistemática não está equilibrada, pois como visto os 
encargos atribuídos aos municípios não são proporcionais à arrecadação que estes são autorizados a realizar. Criou-se uma relação de dependência dos repasses que é prejudicada quando em momento de crise financeira o ente central reduz sua receita, por meio de incentivos fiscais e outros instrumentos fomentadores das atividades econômicas.

A sociedade é diretamente impactada com a diminuição da quantidade e da qualidade dos serviços públicos prestados. O país possui municípios de pequeno porte que possuem arrecadação tributária ínfima, dependendo totalmente dos recursos destinados pelos Estados e pela União para subsistirem, o que implica em questionamento sobre a existência de autonomia para aqueles entes, apesar do status conferido pela Constituição de 1988.

Uma das soluções para a dependência financeira é a criação de mecanismos garantidores da autonomia dos entes subnacionais, como apontou a doutrina. Outra maneira eficaz é a reestruturação do sistema tributário nacional, para o reequilíbrio entre as receitas e os encargos, simplificando e desburocratizando as operações, bem como modernizando as normas tributárias à evolução social e tecnológica ocorrida ao longo do tempo.

Outrossim, o país precisa rever a repartição das receitas e dos encargos entre os entes federativos, além de propiciar que a autonomia e a independência financeira dos Estados, Distrito Federal e municípios possam aumentar. Quanto mais dependentes da União, menos desenvolvimento econômico terá o Brasil.

No modo em que estão sendo praticados atualmente os repasses financeiros aos municípios, nota-se que não ocorre o cumprimento dos princípios e objetivos fundamentais do Estado brasileiro em sua integralidade, assim como se tem impedido ao sistema tributário nacional de alcançar o equilíbrio necessário.

Não basta que o Poder Judiciário seja chamado a interferir toda vez que uma omissão legislativa estiver obstando atividades; organizar as normas tributárias para que o federalismo fiscal tenha mais equilíbrio é imprescindível para o Brasil ter um ritmo de desenvolvimento econômico em patamares competitivos com outros países. 


\section{REFERÊNCIAS}

ASSUNÇÃO, M. C. Incentivos Fiscais e Desenvolvimento Econômico: a função das normas tributárias indutoras em tempos de crise. Revista Finanças Públicas - XV Prêmio Tesouro Nacional, 2010, p. 2- 41.

AZEVEDO, S.; MELO, M. A. A política da reforma tributária: federalismo e mudança constitucional. In Revista Brasileira de Ciências Sociais, São Paulo, v.12, n. 35, fev. 1997. Disponível em: < http://www.scielo.br/scielo.php?script=sci arttext\&pid =S0102-69091997000300006 > . Acesso em: 31 out. 2017.

BARBOSA, Fernando de Holanda, et al. Federalismo Fiscal, Eficiência e Equidade: uma proposta de reforma tributária. In: BARBOSA, F. H. (Coord.). Tributação na Economia Globalizada: debate sobre princípios e uma proposta de reforma tributária. São Paulo: Forma 3, 1999. p. 221-349.

BARRERA, A. W.; ROARELLI, M. L. M. Relações Fiscais Intergovernamentais. In AFFONSO, R. B. A.; SILVA, P. L. B. (Org.). Reforma Tributária e Federação. São Paulo: UNESP, 1999. p. 129-160.

BRASIL. Constituição da República dos Estados Unidos do Brasil (de 24 de fevereiro de 1891). Disponível em: < http://www.planalto.gov.br/ccivil_03/constituicao/ constituica091.htm > Acesso em: 08 jan. 2018.

BRASIL. Constituição da República dos Estados Unidos do Brasil (de 16 de julho de 1934). Disponível em: < http://www.planalto.gov.br/ccivil_03/constituicao/ constituicao34.htm > Acesso em: 08 jan. 2018.

BRASIL. Constituição dos Estados Unidos do Brasil (de 10 de novembro de 1937). Disponível em: < http://www.planalto.gov.br/ccivil_03/constituicao/constituica037. htm >. Acesso em: 08 jan. 2018.

BRASIL. Constituição dos Estados Unidos do Brasil (de 18 de setembro de 1946). Disponível em: < http://www.planalto.gov.br/ccivil_03/constituicao/constituicao46. htm > . Acesso em: 08 jan. 2018. 
BRASIL. Constituição da República Federativa do Brasil de 1988. Disponível em: $<$ http://www.planalto.gov.br/ccivil_03/constituicao/constituicaocompilado.htm > . Acesso em: 05 jan. 2018.

BRASIL. Lei n. 5.172, de 25 de outubro de 1966. Dispõe sobre o sistema tributário nacional e institui normas gerais de direito tributário aplicáveis à União, Estados e Municípios. Disponível em: <http://www.planalto.gov.br/ccivil_03/leis/ L5172Compilado.htm>. Acesso em: 04 jan. 2018.

BRASIL. Supremo Tribunal Federal. Ação Direta de Inconstitucionalidade por Omissão (ADO) n. 25/DF. Rel. Min. Gilmar Mendes. Julg. 30/11/2016. Disponível em: <http://www.stf.jus.br/portal/jurisprudencia/listarJurisprudencia. asp?s1 = \%28FEDERALISMO + FISCAL\%29\&base = baseAcordaos\&url = http:// tinyurl.com/zc89vaj>. Acesso em: 05 jan. 2018.

CARRAZZA, R. A. Curso de Direito Constitucional Tributário. 29. ed. rev. ampl. e atual. São Paulo: Malheiros, 2013.

COSTA, N. N. Direito Municipal Brasileiro. 7. ed. Rio de Janeiro: Forense, 2015.

DAIN, S. Experiência Internacional e especificidade brasileira. In: AFFONSO, R. B. A.; SILVA, L. B. (Org.). Reforma tributária e Federação. São Paulo: UNESP, 1995, p. $21-42$.

DOMINGUES, J. M. Federalismo Fiscal Brasileiro. Revista Nomos, v. Edição Comemorativa dos 30 anos do Mestrado em Direito/UFC, 2007, p. 137-143. Disponível em: < http://repositorio.ufc.br/bitstream/riufc/12333/1/2007_art_jmdomingues. pdf $>$. Acesso em: 08 jan. 2018.

FERREIRA, R. N. A reforma essencial II: Reforma Tributária - esqueçam a reforma tributária [uma análise independente, sob a ótica empresarial, dos debates tributários pós 2002]. Brasília - DF: Senac, 2016.

MANSUR, D. O. U. Os novos critérios de rateio do FPE: considerações à luz do federalismo cooperativo e do princípio da solidariedade. In CAMPOS, C. A. A.; IBRAHIM, F. Z.; OLIVEIRA, G. G. V. (Org.). Estudos de Federalismo e Guerra 